\title{
SISTEM MONITORING VOLUME AIR MENGGUNAKAN SENSOR ULTRASONIK DAN MONITORING OUTPUT VOLUME AIR MENGGUNAKAN FLOW METER BERBASIS ARDUINO
}

\author{
Servinta Damayanti Br Pelawi, Saiful Manan \\ Program Studi Diploma III Teknik Elektro \\ Sekolah Vokasi Universitas Diponegoro
}

\begin{abstract}
Servinta Damayanti Br Pelawi, Saiful Manan, in this paper explain that method of realization of making purification and monitoring volume of water, purification of water using small molecules such as sand, charcoal, cotton, etc. and monitoring the volume of water using the HC-SRO4 ultrasonic sensor. where this ultrasonic sensor will detect the water inside the sensor distance sensor to objects that is $2 \mathrm{~cm}$ and $25 \mathrm{~cm}$. When the water has reached the limit of $2 \mathrm{~cm}$ and $15 \mathrm{~cm}$ then the buzzer will light up giving a warning. and will display on the HMI in the form of cm, to run the pump we click the start button at hmi the pump will turn on and the water inside the reservoir will enter reverse osmosis, Ro will process water, clean water will be read by the flow meter, flow meter will detect incoming water and will display the results in the HMI in the form liter, and Arduino UNO is used as a control system for HMI output input signals, sensors, flow meters, and buzzers.
\end{abstract}

Keywords: Ultrasonic Sensor, Buzzer, Flow Meter, Arduino Uno and HMI.

\section{PENDAHULUAN}

Air bersih merupakan kebutuhan dasar makhluk hidup karena air berperan penting dalam proses kehidupan. Air yang biasanya kita pakai berasal dari beberapa sumber,antara lain air danau,air laut dan air sumur,kualitas air dari berbagai sumber tersebut memiliki karakteristik kualitas dan kuantitas yang berbeda-beda. Permasalah saat ini sangat sulit memenuhi kebutuhan air bagi kehidupan manusia dengan itu penulis membuat alat pemurnian air dan monitoring volume air.

Pemurnian air tersebut menggunakan molekul-molekul seperti kapas ,arang,batu,pasir ,pemurnian air tersebut akan di saring oleh beberapa komponen di atas dan dan masuk ke dalam mesin reverse osmosis dan di dalam mesin revese osmosis juga akan di saring air yang bersih dan kurang bersih .air yang di masukkan ke dalam tandon pertama yang terdapat molekul_molekul tersebut maka ketika air berada dalam $2 \mathrm{~cm}$ dan $15 \mathrm{~cm}$ sensor ultrasonik akan bekerja mendeteksi bendadan akan mmberi peringatan bunyi dngan buzzer,untuk mngaktifkan pompa kita klik tombol start di HMI maka pompa akan aktif dan mengalir air ke dalam mesin Reverse Osmosis didalam Ro air akan di deteksi bersih atau kurang bersih air yang brsih akan masuk kedalam Flow Meter dan flow meter akan bekerja mendeteksi air berupa liter,dan akan di masukkan ke penampungan, dan air yang kotor dibuang .

\section{Flow Meter}

Flow meter adalah alat untuk mengukur jumlah atau laju aliran volumetrik cairan atau gas dari suatu fluida yang mengalir dalam suatu pipa atau terbuka. Magnetic flow meter atau Flow meter electromagnetic merupakan jenis flow meter yang prinsip kerjanya menggunakan hukum faraday yaitu bila suatu fluida konduktif elektrik melewati pipa transduser, maka fluida akan bekerja sebagai konduktor yang

bergerak memotong medan magnet yang dibangkitkan oleh kumparan magnetik dan transduser, sehingga timbul tegangan listrik induksi.

Magnetic flow meter atau Flow meter electromagnetic merupakan jenis flow meter yang prinsip kerjanya menggunakan hukum faraday yaitu bila suatu fluida konduktif elektrik melewati pipa transduser, maka fluida akan bekerja sebagai konduktor yang bergerak memotong medan magnet yang dibangkitkan oleh kumparan magnetik dan transduser, sehingga timbul tegangan listrik induksi. Gambar 1 merupakan bentuk fisik dari flow meter.

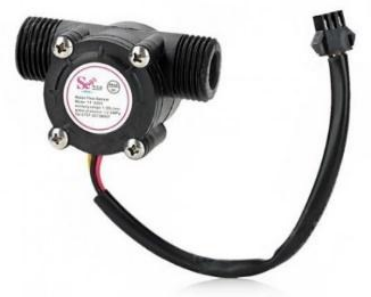

Gambar 1. Flow Meter

\section{Sensor Ultrasonik}

Sensor ultrasonik adalah alat elektronika yang kemampuannya bisa mengubah dari energy listrik menjadi energi mekanik dalam bentuk gelombang suara ultrasonik.Sensor ini terdiri dari rangkaian pemancar ultrasonic yang dinamakan transmitter dan penerima ultrasonik yang disebut receiver. Alat ini digunakan untuk mngukur gelombang ultrasonik.Gelombang ultrasonik adalah gelombang mekanik yang memiliki ciri-ciri longitudinal dan biasanya memiliki frekuensi diatas 20 
Khz.Gelombang ultrasonic dapat merambat melalui zat padat,cair maupun gas.Gelombang ultrasonik adalah gelombang rambatan.energi dan momentum mekanik sehingga merambat melalui ketiga element tersebut sebagai interaksi dengan molekul dan sifat enersial medium yang dilaluinya.

Sensor Ultrasonik merupakan sensor yang memanfatkan bunyi dengan frekuensi ultrasonik.Frekuensi ini tidak dapat didengar oleh manusia karena memiliki frekuensi ini tidak dapat didengar oleh manusia karena memiliki frekuensi di atas $20 \mathrm{Khz}$,Sensor ini sendiri biasanya menggunakan Rx.Sehingga umunya sensor ini di pakai untuk pengukur jarak. Gambar 2 merupakan bentuk fisik sensor ultrasonic.

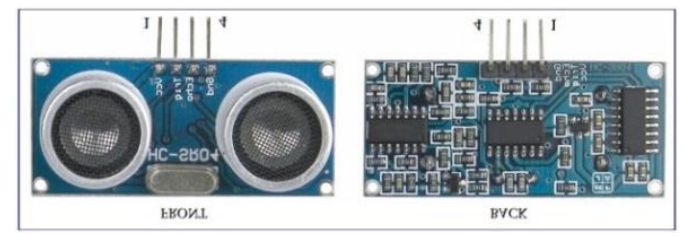

Gambar 2. Tampilan Sensor Ultrasonik

\section{Arduino Uno}

Arduino dikatakan sebagai sebuah platform dari physical computing yang bersifat programable yang dapat di program. Pertama-tama perlu dipahami bahwa kata "platform" di sini adalah sebuah pilihan kata yang tepat. Arduino tidak hanya sekedar sebuah alat pengembangan, tetapi ia adalah kombinasi dari hardware, bahasa pemrograman dan Integrated Development Environment (IDE) yang canggih. IDE adalah sebuah software yang sangat berperan untuk menulis program, meng-compile menjadi kode biner dan meng-upload ke dalam memory microcontroller. Ada banyak projek dan alat-alat dikembangkan oleh akademisi dan profesional dengan menggunakan Arduino, selain itu juga ada banyak modul-modul pendukung (sensor, tampilan, penggerak dan sebagainya) yang dibuat oleh pihak lain untuk bisa disambungkan dengan Arduino. Arduino berevolusi menjadi sebuah platform karena ia menjadi pilihan dan acuan bagi banyak praktisi. Gambar 3 merupakan bentuk fisik dari board Arduino uno.

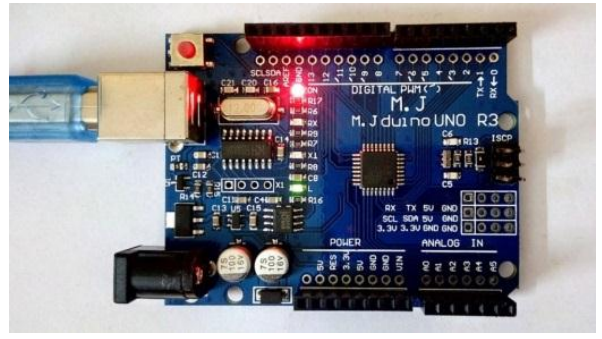

Gambar 3. Arduino

Secara umum Arduino terdiri dari dua bagian, yaitu:

- Hardware

Papan input/output (I/O)
- Software

Software Arduino meliputi IDE untuk menulis program, driver untuk koneksi dengan komputer, contoh program dan library untuk pengembangan program. Komponen utama di dalam papan Arduino adalah sebuah microcontroller 8 bit dengan merk ATmega yang dibuat oleh perusahaan Atmel Corporation. Berbagai papan Arduino menggunakan tipe ATmega yang berbeda-beda tergantung dari spesifikasinya, sebagai contoh Arduino Uno menggunakan ATmega328 sedangkan Arduino Mega 2560 yang lebih canggih menggunakan ATmega2560. Berikut adalah diagram blok sederhana dari sebuah microcontrolor AT mega 328 yang di pakai pada Ardunio Relai pengendali elektromekanis (an elektromechanical relay = EMR) adalah saklar magnetis. Relai ini menghubungkan rangkaian beban $\mathrm{ON}$ atau OFF dengan pemberian energi elektromagnetis, yang membuka atau menutup kontak pada rangkaian. Untuk menggerakan relay, daya (arus/tegangan) dari mikrokontroller kurang mencukupi sehingga perlu penguat (driver).

\section{RANGKAIAN KESELURUHAN}

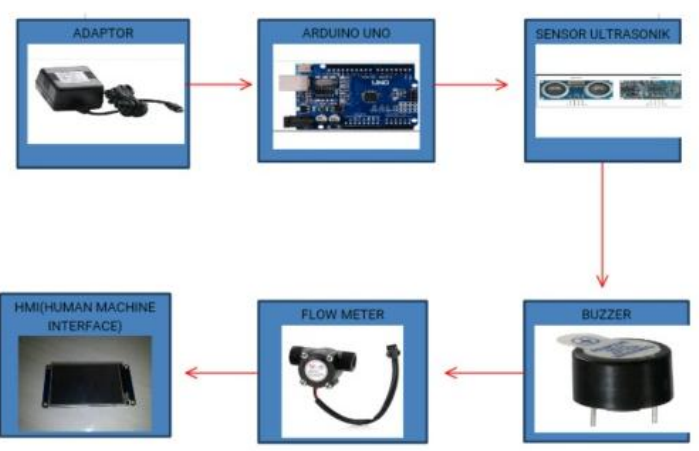

Gambar 4. Blok Diagram Rangkaian Keseluruhan

Gambar 4 menunjukkan diagram blok sistem monitoring yang dimaksud. Sistem dibagi menjadi beberapa bagian yang dapat dijelaskan sebagai berikut.

a. Catu Daya Charger 9V

Merupakan rangkaian yang berfungsi mensuplai Arduino Uno.

b. Arduino Uno

Arduino Uno digunakan sebagai pengendali inputan dan outputan system, komunikasi data serta menjalankan sistem secara keseluruhan.

c. Flow Meter

Berfungsi untuk menghitung keluaran air yang diproses dari reverse osmosis, dan flow meter masuk di pin 2 arduino uno. 


\section{d. Sensor Ultrasonik}

Berfungsi untuk memonitoring isi air yang ada di dalam tandon,yang akan di pantau penuh atau kurang air yang ada di dalam tandon.Sensor Ultrasonik masuk di kaki 12 dan 13 di arduino uno di kaki 12 dipakai ultrasonic echo dan di kaki 13 di pakai ultrasonic trigger.

e. HMI 3,2

Berfungsi untuk menampilkan isi yang ada di dalam tandon,dan menampilkan keluaran air yang di buat flow meter . total volume, jarak benda ke sensor ultrasonic HMI masuk ke kaki tx dan rx di arduino .

Untuk cara kerja dari rangkaian keseluruhan pada alat sistem monitoring volume air berbasis arduino uno dengan alur dari flowchart kerja rangkaian

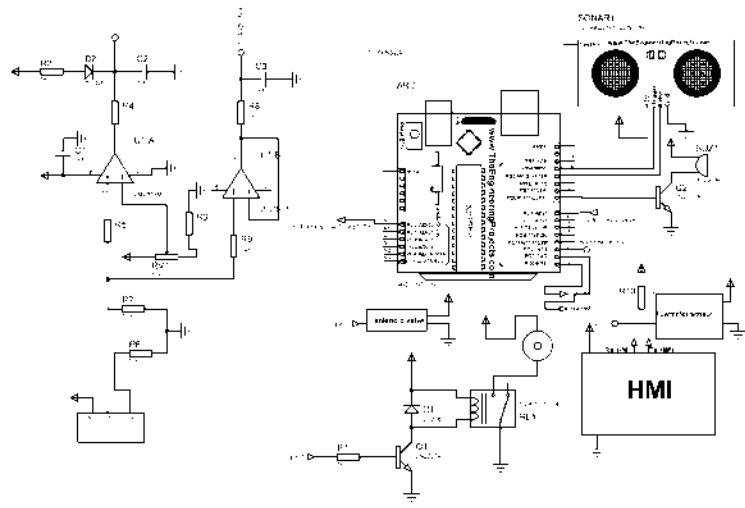

Gambar 5. Rangkaian Keseluruhan

Gambar 5 menunjukkan gambar rangkaian keseluruhan sistem. Sesuai dengan rangkaian keseluruhan diatas system akan aktif apabila mendapat tegangan $9 \mathrm{~V}$ yang berasal dari rangkaian catu daya.pertama kita mengaktifkan pompa, pompa tidak akan langsung aktif ketika sudah ada sumber,karena sudah di atur dalam arduino,kita akan menekan tombol start di HMI untuk menjalankan pompa,maka pompa akan aktif, memasukkan air kedalam tandon,Sensor Ultrasonik akan bekerja ketika ketinggian muka air yang berada di dalam tandon mencapai batas yang ditentukan.Hasil dari sistem dapat ditampilkan dalam satuan $\mathrm{cm}$.

Setelah Sensor Ultrasonik mendeteksi laju aliran air pada tandon maka buzzer akan menyala memberikan peringatan.dan akan menampilkan hasil berupa $\mathrm{cm}$ di HMI.Setelah disetting maka air akan mengalir masuk pompa untuk diteruskan ke membran RO hingga air ditampung ke tandon akhir.Setelah melewati Reverse Osmosis maka air akan keluar dan karena valve telah terbuka saat start maka air langsung diteruskan ke flow meter yang akan dideteksakan dan dihitung langsung oleh flow meter berupa liter. lalu air akan mengisi tandon yang telah dibuat agar sensor kekeruhan dapat medeteksi nilai kekeruhan air hasil system filtrasi ini. Semua data yang didapat oleh system ini secara keseluruhan akan ditampilkan pada HMI. Agar semua perubahan kerja system dapat diketahui dengan baik. Dan setelah data yang diperlukan cukup, bisa menekan tombol stop untuk menghentikan proses dan menutup valve agar air tidak masuk ke dalam tandon hasil.

\section{PENGUJIAN DAN ANALISA}

Tabel 1. Hasil Pengukuran Flow Meter

\begin{tabular}{cc}
\hline Waktu & Volume \\
\hline 5 Menit & $4,5 \mathrm{Cm}$ \\
10 Menit & $9 \mathrm{Cm}$ \\
15 Menit & $14 \mathrm{Cm}$ \\
20 Menit & $17 \mathrm{Cm}$ \\
\hline
\end{tabular}

Tabel 2. Hasil Pengukuran Sensor Ultrasonik

\begin{tabular}{cc}
\hline Waktu & Volume \\
\hline $5 \mathrm{Menit}$ & $5 \mathrm{Cm}$ \\
10 Menit & $9,7 \mathrm{Cm}$ \\
15 Menit & $13 \mathrm{Cm}$ \\
20 Menit & $17,3 \mathrm{Cm}$ \\
\hline
\end{tabular}

Tabel 1 dan 2 merupakan hasil pengukuran dan percobaan sistem. Dari data percobaan diatas yaitu antara data hasil pengukuran percobaan Flow dan Sensor Ultrasonik Selisih Sedikit. karena bisa saja air yang mengalir dari tandon pertama tidak keluar dari flow karena dalam keadaan keruh.

\section{KESIMPULAN}

Setelah melakukan perancangan, pembuatan benda kerja dan percobaan, maka dapat diperoleh beberapa kesimpulan sebagai berikut :

- Sistem monitoring tinggi muka air menggunakan sensor ultrasonik yang mengukur ketinggian muka air berupa $\mathrm{cm}$ yaitu kedeteksi mulai dari 2 $\mathrm{cm}$ sampai $25 \mathrm{~cm}$.

- Sistem dapat menampilkan nilai ketinggian dalam satuan berupa $\mathrm{cm}$ yang nantinya akan di tampilkan di HMI,Serta memberikan peringatan dengan menyalakan buzzer ketika ketinggian muka air telah mencapai batas yang telah ditentukan.

- Air produksi hasil penyaringan membran pada proses reverse osmosis ini akan di hitung outputannya dengan menggunakan flow meter berupa liter dan akan di tampilkan pada HMI berupa liter,dan air yang dihitung / di deteksi oleh flow meter yaitu air yang sesuai dengan standart.yang sudah layak untuk di konsumsi. 


\section{DAFTAR PUSTAKA}

1. Iqbal, Mohammad. (2014). Rancang Bangun monitoring volume air menggunakan mikrokontroler atmega 8535 berbasis Borland Delphi 7. Semarang: Universitas Diponegoro.

2. Yudhanto,Saktyo. 2012. Tandon Air Otomatis Berbasis Mikrokontroler ATmega 16.

3. Rinalakbar. Alat Ukur Magnetic Flow Meter Diakses pada 10 Januari 2010, 10:31 WIB.

4. Andrianto,Heri,Arduino Belajar Cepat dan Pemrograman .Informatika Bandung. Diakses pada januari 2016.

5. Arin.2016. Pengendali Tekanan Pompa dngan Pmw(Pulse Width Modulation) Pada Membran Ro .Tugas Akhir Tidak Terpublikasi.Semarang: Universitas Diponegoro. 